\title{
The IL-2 Defect in Systemic Lupus Erythematosus Disease Has an Expansive Effect on Host Immunity
}

\author{
Linda A. Lieberman and George C. Tsokos \\ Division of Rheumatology, Department of Medicine, Beth Israel Deaconess Medical Center, Harvard Medical School, 330 Brookline \\ Avenue, CLS 937, Boston, MA 02115, USA \\ Correspondence should be addressed to Linda A. Lieberman, llieber1@bidmc.harvard.edu \\ Received 17 January 2010; Accepted 16 March 2010 \\ Academic Editor: Timothy B. Niewold \\ Copyright $\odot 2010$ L. A. Lieberman and G. C. Tsokos. This is an open access article distributed under the Creative Commons \\ Attribution License, which permits unrestricted use, distribution, and reproduction in any medium, provided the original work is \\ properly cited. \\ IL-2 production is decreased in systemic lupus erythematosus (SLE) patients and affects T cell function and other aspects of host \\ immunity. Transcription factors regulating IL-2 production behave aberrantly in SLE T cells. In addition to IL-2 dysregulation, \\ other IL-2 family members (IL-15 and IL-21) are abnormally expressed in SLE. Decreased IL-2 production in SLE patients leads \\ to many immune defects such as decreased $\mathrm{T}_{\text {reg }}$ production, decreased activation-induced cell death (AICD), and decreased \\ cytotoxicity. IL-2 deficiency results in systemic dysregulation of host immune responses in patients suffering from SLE disease.
}

\section{Introduction}

IL-2 is a multifunctional cytokine primarily produced by T cells and is necessary for $\mathrm{T}$ cell activation, proliferation, and contraction. It has been reported that production of IL-2 is decreased in patients with systemic lupus erythematosus (SLE) and this defect affects multiple aspects of host immunity [1]. SLE is a complex autoimmune disease characterized by autoantibody production and widespread inflammation. Patients with this chronic disease cycle between periods of controlled disease and disease flare involving various organs and tissue.

Defective IL-2 production is one of many factors involved in the immune dysregulation responsible for this disease. As reported in patients, an IL-2 defect is observed in various SLE murine models and murine models have provided much information about the relationship between IL-2 and SLE. Furthermore, other IL-2 family members (IL-15 and IL-21) have been shown to be dysregulated in SLE disease. It has been found that the transcriptional regulators responsible for the transcription or suppression of IL-2 production are imbalanced in SLE T cells [2] and this explains the reduced IL-2 levels found in SLE patients.

One of the consequences of decreased IL-2 production is a reduction in the number of regulatory $\mathrm{T}$ cells $\left(\mathrm{T}_{\text {reg }}\right)$ in these patients. $\mathrm{T}_{\text {reg }}$ cells control expansion of autoreactive $\mathrm{T}$ cells and therefore are important in inhibiting autoimmunity. The decreased IL-2 production in SLE patients affects additional immune functions other than $\mathrm{T}$ cell proliferation. Activation-induced cell death (AICD), an IL-2 regulated process which is necessary for the down-regulation of expanded $\mathrm{T}$ cell clones, is defective in SLE T cells $[3,4]$. IL2 is also necessary for $\mathrm{CD} 8^{+} \mathrm{T}$ cell effector functions and the development of $\mathrm{CD}^{+} \mathrm{T}$ cell memory [5]. A defect in $\mathrm{CD} 8^{+} \mathrm{T}$ cell cytotoxic function leads to an increased chance of intracellular infection which could be deadly for SLE patients.

\section{Defective IL-2 Production in SLE}

It has long been known that IL-2 production is defective in SLE patients. Early in vitro studies examined SLE T cell response to mitogens. $\mathrm{T}$ cells were stimulated with the mitogen phytohemagglutinin (PHA) and it was found that they were unable to produce high levels of IL-2; a greater defect was observed in $\mathrm{T}$ cells isolated from patients with active disease [6]. Interestingly, it was observed that PHAactivated SLE T cells respond to exogenous IL-2 stimulation, indicating that IL-2R expression is normal on these cells [7]. Furthermore, it has been suggested that the IL-2R is upregulated on T cells from SLE patients with active disease as compared to those with inactive disease [8]. However, it seems that the IL-2R found on these SLE T cells is not 
the high affinity receptor and therefore these cells are not optimally responsive to exogenous IL-2 [9].

Why do SLE T cells produce less IL-2? IL-2 production is upregulated through an autocrine (or paracrine) loop therefore it would seem logical that a defect in the $\mathrm{T}$ cell receptor (TCR) would result in decreased transcription of IL2. Indeed, one of the TCR components, the $\mathrm{CD} 3 \zeta$ chain, is significantly decreased in SLE T cells [10] and in its place is the closely related common $\gamma$ chain of the immunoglobulin receptors $(\mathrm{FcR} \gamma)$, a molecule not normally expressed in $\mathrm{T}$ cells [11]. But this substitution results in increased TCR responsiveness as evidenced by expedited calcium flux and greater tyrosine phosphorylation of TCR-associated signaling molecules upon $\mathrm{T}$ cell activation [12]. Therefore the unusual TCR configuration present in SLE T cells does not seem to contribute to the decrease in IL-2 production.

The molecular mechanism of the IL-2 defect has now been clarified. The decreased IL-2 production observed in SLE patients is based on the relationship between the transcription factors CRE-binding protein (CREB) and CREmodulator (CREM). These two transcription factors share a binding site 180 basepairs upstream of the IL-2 promoter and are responsible for activating or repressing IL-2 production (Figure 1). CREB occupies the binding site in resting $\mathrm{T}$ cells and upon activation, it is phosphorylated (pCREB) thereby promoting IL-2 transcription. IL-2 transcription is repressed by the replacement of PCREB by phosphorylated CREM (pCREM). SLE patients have higher levels of CREM than CREB, resulting in decreased IL-2 production [2]. It is not clear why the CREB/CREM balance is irregular in SLE $\mathrm{T}$ cells, but there is evidence to suggest that the enzyme CaMKIV which phosphorylates CREM leads to an increase in this suppressive factor in SLE T cells [13]. Additionally, SLE T cells have increased levels of the serine/threonine phosphatase PP2A, the phosphatase primarily responsible for the dephosphorylation of CREB, and this contributes to decreased IL-2 production [14].

\section{IL-2 in Murine Models of SLE}

There are numerous murine models for studying SLE, but as this disease is complex and variable from patient to patient it has not been possible to create one mouse strain that represents the full spectrum of disease. As described above, IL-2 is decreased in human SLE, but is this reflected in the murine models?

One of the most commonly studied murine models of SLE is the MRL/lpr strain. These mice carry the lpr mutation in the apoptotic protein Fas. They spontaneously develop lupus-like disease beginning at twelve weeks of age and subsequently display skin lesions, lymphadenopathy, autoantibody production, and proteinuria and often succumb to death from glomerulonephtritis between seventeen (female) to twenty-two weeks (male) of age. These mice exhibit lymphoproliferation by three months of age which is not commonly seen in patients with SLE. It was found that IL2 production and responsiveness is decreased in MRL/lpr mice and as mice age (and develop severe disease), this defect becomes more pronounced [15]. Furthermore, as described

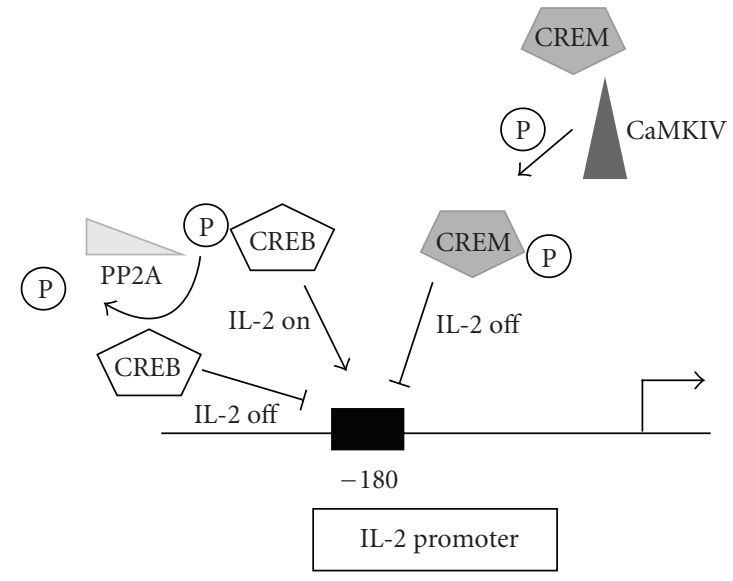

FIgURE 1: IL-2 transcriptional regulation in T cells. Upon $\mathrm{T}$ cell activation, CREB is phosphorylated leading to IL-2 transcription. CREM is also phosphorylated upon $\mathrm{T}$ cell activation and it will displace pCREB to shut down IL-2 transcription. CaMKIV is upregulated in SLE and it is responsible for phosphorylation of CREM. PP2A is also upregulated in SLE and this phosphatase dephosporylates CREB.

for humans, mitogenic or antigenic stimulation of MRL/lpr $\mathrm{T}$ cells results in weak IL-2 production [15-17].

$\mathrm{BXSB} / \mathrm{Ya} a$ mice develop lupus in male mice due to the Y-linked autoimmune accelerator (Yaa) gene. Similar to the MRL/lpr mice, the male BXSB/Yaa mice develop lupus rapidly and fifty percent will succumb to glomerulonephritis by five months of age [18]. Like the MRL/lpr mice, male BXSB mice display a defective IL-2 mitogenic response as early as six weeks of age [15].

The NZB $\times$ NZW F1 murine model develops lupus at a slower rate than the other strains mentioned. The female NZB $\times$ NZW F1 mice will succumb to disease at approximately eight months of age. Therefore, it is not surprising that NZB $\times \mathrm{NZW}$ F1 T cells do not show a decreased mitogenic response until 7.5 months, as these mice develop lupus-like disease slower than the other two strains [15]. Amongst these commonly studied murine models of SLE, the defect in IL-2 production and responsiveness is similar to that observed in humans.

\section{IL-2/IL-2R Deficient Mice}

Much of what is known about IL-2 regulation of the immune response has been realized from studies using the IL- 2 or IL-2R knockout mice. Mice lacking IL-2 or IL-2R initially appear normal, but by four weeks of age they develop spontaneous autoimmune disease. The early disease displayed by the IL-2 $2^{-/}$mice is characterized by splenomegaly, lymphadenopathy, and severe anemia. If they survive beyond nine weeks of age, they will develop irritable bowel disease leading to death $[19,20]$. Similarly, IL-2R $\beta^{-/-}$mice are runted by four weeks of age and develop splenomegaly, lymphadenopathy, and anemia caused by autolysis. It has also been noted that these mice have increased serum IgG1 levels and high concentrations of autoantibodies, but they do 


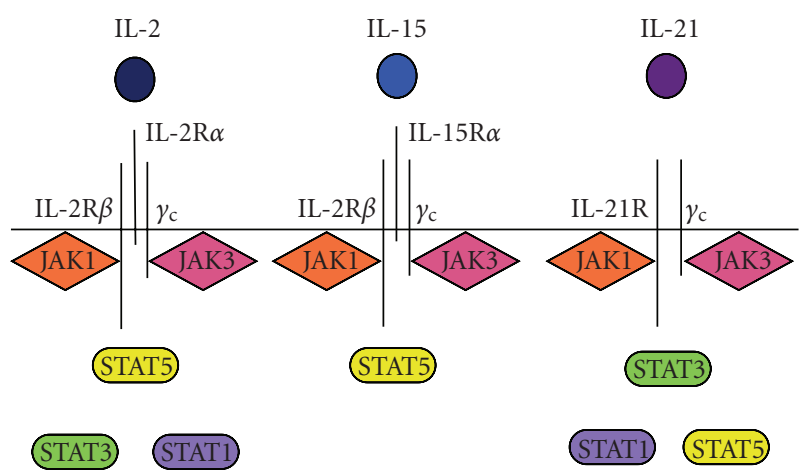

FIGURE 2: IL-2 superfamily. IL-2, IL-15, and IL-21 are closely related in receptor binding, and function. IL-2 and IL-15 bind trimeric receptors and two of the three chains (IL-2R $\beta, \gamma_{c}$ ) are the same, while each cytokine binds a unique third component of the receptor (IL- $2 \alpha$ or IL-15 $\alpha$, respectively). The dimeric IL-21R consists of the $\gamma_{c}$ chain, shared with IL-2R and IL-15R, and a unique chain, IL21R. All three cytokines utilize the Janus kinases signaling molecules JAK1 and JAK3. IL-2 and IL-2 1 can activate STAT1/3/5 while IL-15 is only known to activate STAT5. While IL-2 and IL-21 can activate multiple STAT family members, IL-2 primarily signals through STAT5 homodimers whereas IL-21 mostly signals through STAT3 homodimers.

not develop irritable bowel disease. Nevertheless, these mice only survive about twelve weeks before succumbing to severe autoimmunity [21].

It has more recently been discovered that the lymphoproliferation observed in the IL-2/IL- $2 \mathrm{R}^{-/-}$mice is due to the greatly reduced number of regulatory $\mathrm{T}$ cells $\left(\mathrm{T}_{\mathrm{reg}}\right)$ found in the periphery [22]. Similarly, regulatory $\mathrm{T}$ cells are decreased in SLE patients (discussed in Section 6). Unlike the knockout mice, SLE patients do not exhibit extreme lymphoproliferation but they do have some, albeit reduced, levels of IL-2. Nevertheless, IL-2/IL-2R deficient mice present with many of the other characteristics observed in SLE patients, such as autoantibody production, lymphadenopathy, and decreased $\mathrm{T}_{\text {reg }}$ cells.

\section{Other IL-2 Family Members and SLE}

Since IL-2 is integral to maintaining a healthy immune system, it is not surprising there is some redundancy of IL2 function in host immunity. The IL-2 superfamily consists of IL-2, IL-15, and IL-21 (Figure 2). The IL-2R and IL-15R share two of their three receptor chains (IL-2R $\beta$ and $\gamma_{c}$ ) while the IL-21R shares the common gamma chain $\left(\gamma_{\mathrm{c}}\right)$ with the others and binds a unique receptor chain (IL-21R). All three cytokine receptors are associated with JAK1 and JAK3, but IL-2 and IL-15 signal primarily through STAT5, whereas IL21 primarily signals through STAT3 (though it does activate STAT5).

Similar to IL-2, IL-15 can expand T cell populations and mice lacking IL-15 have greatly reduced numbers of $\mathrm{NK}$, NKT, IEL, and $\mathrm{CD} 8^{+} \mathrm{T}$ cells, suggesting a role for this cytokine in development and homeostasis of these cell populations [23]. Patients with SLE have increased serum levels of IL-15, regardless of disease state, and this may contribute to the pathogenesis of disease $[24,25]$. IL-15 has also been observed in increased levels in synovial joints and shown to play a role in arthritic inflammation due to activation of synovial T cells [26].

IL-21 is produced by T cells and it affects the function of T, NK, NKT, and B cells [27]. IL-21 enhances NK and CD8 ${ }^{+}$ $\mathrm{T}$ cell cytotoxicity, and overexpression of IL-21 results in an increase in memory $\mathrm{CD} 8^{+} \mathrm{T}$ cells [28]. IL-21 production is increased in some murine models of SLE [29] and particular polymorphisms of the IL-21 gene have been described in SLE patients [30]. It has been shown in the BXSB/Yaa murine model that IL-21 is integral to SLE development as deletion of the IL-21R in these mice prevents disease progression [31]. While the function of IL-21 on T or NK cells may be redundant with IL-2 or IL-15, IL-21 uniquely promotes activation and plasma cell differentiation of peripheral B cells [32]. Patients with SLE have decreased IL-21R expression in their peripheral B cells and this is associated with nephritis and high levels of autoantibodies [33]. Additionally, IL-21 is also necessary for activation-induced death of expanded $\mathrm{B}$ cells $[29,32]$. While these studies suggest a role for IL-15 and IL-21 in SLE pathogenesis, the significance of these cytokines in human SLE disease is not clear and warrants further study.

\section{Regulatory $T$ Cells $\left(T_{\text {reg }}\right)$ and SLE}

Regulatory $\mathrm{T}$ cells $\left(\mathrm{T}_{\text {reg }}\right)$ are necessary for maintaining tolerance to self antigens and they are able to do this by suppressing self-reactive $\mathrm{T}$ cells. Natural $\mathrm{T}_{\text {reg }}$ cells develop in the thymus, but induced $\mathrm{T}_{\text {reg }}$ cells can be derived from a subset of activated $\mathrm{CD} 4^{+} \mathrm{T}$ cells in the periphery. Development and homeostasis of the $\mathrm{CD} 4^{+} \mathrm{CD} 25^{+} \mathrm{Foxp}^{+} \mathrm{T}_{\text {reg }}$ cell subset is dependent on IL-2. Mice lacking the $\mathrm{T}_{\text {reg }}$ specific transcription factor Foxp 3 completely lack $\mathrm{T}_{\text {reg }}$ cells and are severely ill due to systemic autoimmunity. Decreased IL-2 leads to a decrease in $\mathrm{T}_{\text {reg }}$ population with concurrent autoimmunity due in part to excessive lymphoproliferation. It should be noted that $\mathrm{T}_{\text {reg }}$ cells are not completely dependent on IL-2 for development as evidenced by the low numbers of $\mathrm{T}_{\text {reg }}$ cells present in IL-2/IL-2R knockout mice [34].

$\mathrm{T}_{\text {reg }}$ cells are decreased in SLE and there is evidence to suggest that the number of $\mathrm{T}_{\text {reg }}$ cells in SLE patients may conversely relate to the severity of disease [38]. It was observed that in pediatric SLE patients, those with active disease had fewer $T_{\text {reg }}$ cells and this inversely correlated with the Systemic Lupus Erythematosus Disease Activity Index (SLEDAI) score and serum anti-double-stranded DNA levels [39]. It has been reported (in adult samples) that expression of FOXP3 is decreased in $\mathrm{T}_{\text {reg }}$ cells from SLE patients with active disease and therefore these cells function poorly as suppressors, while patients with inactive disease express more FOXP3 in their $\mathrm{T}_{\text {reg }}$ cells and these cells have greater suppressor activity. Furthermore, in vitro stimulation through the TCR of the FOXP $3^{\text {low }} \mathrm{T}_{\text {reg }}$ cells from patients with active disease results in an increase in FOXP3 expression and restoration of $\mathrm{T}$ cell suppressor function, thereby indicating that these cells have a reversible defect [40]. It should be noted that though both decreased IL-2 levels and decreased $\mathrm{T}_{\text {reg }}$ cells have been 
observed in SLE patients, a definitive link between these two observations has not been made.

\section{Activation-Induced Cell Death (AICD)}

While IL-2 is necessary for T cell activation, it is also needed following clonal expansion to control lymphoproliferation of a $\mathrm{T}$ cell clone. Following antigen stimulation through the TCR, a specific clonal $\mathrm{T}$ cell population will expand to eliminate the foreign object. Once the antigen is no longer present, the process of AICD will destroy the excess effector cells that were expanded to fight the antigen. IL2 is required for this controlled apoptotic mechanism, in conjunction with costimulation through CD95, TNFR1, and other costimulatory molecules $[35,36]$. Furthermore, IL-2 regulates AICD in $\mathrm{CD}^{+} \mathrm{T}$ cells by downregulating IL-2R $\gamma$ as this receptor chain is associated with the survival of the cell [37]. It has been found that SLE patients are more resistant to AICD due to decreased levels of intracellular TNF $\alpha$ and upregulation of COX2 $[3,4]$.

\section{IL-2 and Cytoxicity}

IL-2 is necessary for the development of $\mathrm{CD}^{+} \mathrm{T}$ cell/NK cell cytoxicity. These cell types are important for fighting infection, and cytotoxic $\mathrm{T}$ lymphocytes (CTLs) cells are crucial for the destruction of virally infected cells. Some insight into the role of IL-2 in CTL development comes from a derivative of the IL- $2 \mathrm{R} \beta^{-/-}$mouse that has thymic transgenic expression of IL- $2 \mathrm{R} \beta$ which results in mice lacking the characteristic autoimmunity observed in IL$2 \mathrm{R}^{-/-}$mice, and contains IL-2 nonresponsive $\mathrm{T}$ cells in the periphery. $\mathrm{T}$ cells from these mice can divide a few times following co-stimulation of the TCR, but they fail to expand further, and are unable to properly upregulate perforin and granzyme $\mathrm{B}$, the hallmarks of $\mathrm{CD}^{+} \mathrm{T}$ cell cytotoxicity [43, 44]. Additional support for the IL-2 requirement in CTL expansion and activity is apparent if we look at infection data from the IL-2 $2^{-/-}$mice. Following viral infection of IL-2 $2^{-/-}$ mice with lymphocytic choriomeningitis virus (LCMV), a $\mathrm{T}$ cell response could be detected but it was significantly decreased,suggesting that IL-2 plays an important role in the expansion of virus-specific CTLs [45]. These observations indicate that IL-2 signaling is necessary for the development of cytotoxicity.

IL-2 upregulates the costimulatory molecule CD70 which is necessary for CD8 expansion. It has been demonstrated that when CD70 is blocked and IL-2 is administered, CTL expansion does not occur [46]. $\mathrm{CD}^{+} \mathrm{T}$ cells expressing the co-stimulatory molecule CD27 preferentially secrete IL-2 in response to antigen stimulation [47] and it has recently been shown that CD27-driven IL-2 production in virally infected mice stimulates $\mathrm{CD}^{+} \mathrm{T}$ cell survival in an autocrine manner [48]. These data demonstrate an important role for costimulatory molecules working in concert with IL-2 during CTL activation.

It is not clear how the IL-2 defect in SLE disease affects CTL development and function. Thus far, the data has been conflicting. While there is evidence suggesting a cytotoxic
TAble 1: Consequences of decreased IL-2 production in SLE disease.

(i) Decreased activation-induced cell death (AICD) [3, 4, 35-37].

(ii) Decreased number and function of $\mathrm{T}_{\text {reg }}$ cells [38-40].

(iii) May lead to decreased cytotoxic activity [41, 42].

defect in some patients $[41,42]$, there is also data that asserts that perforin and granzyme B are upregulated in patients with active SLE disease [49]. As seen in many aspects of SLE disease, there may be heterogeneity amongst patients. A CD8 ${ }^{+} \mathrm{T}$ cell defect in SLE patients would be relevant because this may contribute to the increased mortality from infections reported in these patients.

\section{Conclusions}

IL-2 is important for regulating $\mathrm{T}$ cell immunity and therefore affects many aspects of immune responses. Not only is IL-2 dysregulated in SLE, but the IL-2 family members IL-15 and IL-21 are also expressed aberrantly. The decreased production of IL-2 in SLE patients most likely contributes to various immune defects such as decreased $\mathrm{T}_{\text {reg }}$ production, decreased AICD, and potentially decreased CTL responses (Table 1). Interestingly, the decreased FOXP3 expression in SLE $\mathrm{T}_{\text {reg }}$ cells is reversible which may be exploited for therapeutic development. A potential decrease in CTL activity is of utmost importance in SLE as decreased cytotoxicity would make patients more susceptible to intracellular infection. There is evidence that SLE patients have a higher incidence of Epstein Barr virus (EBV) infection [50] and it has been reported that SLE patients have forty times higher viral load and a greater repertoire of antigen-specific B cells for EBV viral proteins [51]. IL-2 deficiency affects multiple regulatory pathways in the host and in the case of SLE this contributes to the multifaceted dysregulation of the immune response.

\section{References}

[1] M. Linker-Israeli, A. C. Bakke, R. C. Kitridou, S. Gendler, S. Gillis, and D. A. Horwitz, "Defective production of interleukin 1 and interleukin 2 in patients with systemic lupus erythematosus (SLE)," Journal of Immunology, vol. 130, no. 6, pp. 2651-2655, 1983.

[2] E. E. Solomou, Y.-T. Juang, M. F. Gourley, G. M. Kammer, and G. C. Tsokos, "Molecular basis of deficient IL-2 production in T cells from patients with systemic lupus erythematosus," Journal of Immunology, vol. 166, no. 6, pp. 4216-4222, 2001.

[3] B. Kovacs, D. Vassilopoulos, S. A. Vogelgesang, and G. C. Tsokos, "Defective CD3-mediated cell death in activated T cells from patients with systemic lupus erythematosus: role of decreased intracellular TNF-alpha," Clinical Immunology and Immunopathology, vol. 81, no. 3, pp. 293-302, 1996.

[4] L. Xu, L. Zhang, Y. Yi, H.-K. Kang, and S. K. Datta, "Human lupus T cells resist inactivation and escape death by upregulating COX-2," Nature Medicine, vol. 10, no. 4, pp. 411415, 2004.

[5] M. A. Williams, A. J. Tyznik, and M. J. Bevan, "Interleukin-2 signals during priming are required for secondary expansion 
of CD8 ${ }^{+}$memory T cells," Nature, vol. 441, no. 7095, pp. 890 893, 2006.

[6] J. Alcocer-Varela and D. Alarcon-Segovia, "Decreased production of and response to interleukin-2 by cultured lymphocytes from patients with systemic lupus erythematosus," Journal of Clinical Investigation, vol. 69, no. 6, pp. 1388-1392, 1982.

[7] P. de Faucal, A. Godard, M. A. Peyrat, J. F. Moreau, and J. P. Soulillou, "Impaired IL2 production by lymphocytes of patients with systemic lupus erythematosus," Annales d'Immunologie, vol. 135D, no. 2, pp. 161-172, 1984.

[8] D. R. Wigfall, R. S. Sakai, D. J. Wallace, and S. C. Jordan, "Interleukin-2 receptor expression in peripheral blood lymphocytes from systemic lupus erythematosus patients: relationship to clinical activity," Clinical Immunology and Immunopathology, vol. 47, no. 3, pp. 354-362, 1988.

[9] H. Ishida, S. Kumagai, H. Umehara, et al., "Impaired expression of high affinity interleukin 2 receptors on activated lymphocytes from patients with systemic lupus erythematosus," Journal of Immunology, vol. 139, no. 4, pp. 1070-1074, 1987.

[10] S. N. Liossis, X. Z. Ding, G. J. Dennis, and G. C. Tsokos, "Altered pattern of TCR/CD3-mediated protein-tyrosyl phosphorylation in $\mathrm{T}$ cells from patients with systemic lupus erythematosus. Deficient expression of the T cell receptor zeta chain," The Journal of Clinical Investigation, vol. 101, no. 7, pp. 1448-1457, 1998.

[11] E. J. Enyedy, M. P. Nambiar, S.-N. C. Liossis, G. Dennis, G. M. Kammer, and G. C. Tsokos, "Fce receptor type I $\gamma$ chain replaces the deficient $\mathrm{T}$ cell receptor $\zeta$ chain in $\mathrm{T}$ cells of patients with systemic lupus erythematosus," Arthritis and Rheumatism, vol. 44, no. 5, pp. 1114-1121, 2001.

[12] G. C. Tsokos, M. P. Nambiar, K. Tenbrock, and Y.-T. Juang, "Rewiring the T-cell: signaling defects and novel prospects for the treatment of SLE," Trends in Immunology, vol. 24, no. 5, pp. 259-263, 2003.

[13] Y.-T. Juang, Y. Wang, E. E. Solomou, et al., "Systemic lupus erythematosus serum IgG increases CREM binding to the IL-2 promoter and suppresses IL-2 production through CaMKIV," Journal of Clinical Investigation, vol. 115, no. 4, pp. 996-1005, 2005.

[14] C. G. Katsiari, V. C. Kyttaris, Y.-T. Juang, and G. C. Tsokos, "Protein phosphatase $2 \mathrm{~A}$ is a negative regulator of IL-2 production in patients with systemic lupus erythematosus," Journal of Clinical Investigation, vol. 115, no. 11, pp. 31933204, 2005.

[15] A. Altman, A. N. Theofilopoulos, R. Weiner, D. H. Katz, and F. J. Dixon, "Analysis of T cell function in autoimmune murine strains. Defects in production of and responsiveness to interleukin 2," Journal of Experimental Medicine, vol. 154, no. 3, pp. 791-808, 1981.

[16] D. Wofsy, E. D. Murphy, J. B. Roths, M. J. Dauphinée, S. B. Kipper, and N. Talal, "Deficient interleukin 2 activity in $\mathrm{MRL} / \mathrm{Mp}$ and C57BL/6J mice bearing the lpr gene," Journal of Experimental Medicine, vol. 154, no. 5, pp. 1671-1680, 1981.

[17] J.-L. Davignon, P. L. Cohen, and R. A. Eisenberg, "Rapid $\mathrm{T}$ cell receptor modulation accompanies lack of in vitro mitogenic responsiveness of double negative $\mathrm{T}$ cells to antiCD3 monoclonal antibody in MRL/Mp-lpr/lpr mice," Journal of Immunology, vol. 141, no. 6, pp. 1848-1854, 1988.

[18] B. Hahn and R. R. Singh, "Animal models of systemic lupus erythematosus," in Dubois' Lupus Erythematosus, D. J. Wallace, Ed., Lippincott Williams \& Wilkin, Philadelphia, Pa, USA, 7th edition, 2007.

[19] H. Schorle, T. Holtschke, T. Hunig, A. Schimpl, and I. Horak, "Development and function of $\mathrm{T}$ cells in mice rendered interleukin-2 deficient by gene targeting," Nature, vol. 352, no. 6336, pp. 621-624, 1991.

[20] B. Sadlack, H. Merz, H. Schorle, A. Schimpl, A. C. Feller, and I. Horak, "Ulcerative colitis-like disease in mice with a disrupted interleukin-2 gene," Cell, vol. 75, no. 2, pp. 253-261, 1993.

[21] H. Suzuki, T. M. Kundig, C. Furlonger, et al., "Deregulated T cell activation and autoimmunity in mice lacking interleukin2 receptor $\beta$," Science, vol. 268, no. 5216, pp. 1472-1476, 1995.

[22] T. R. Malek, A. Yu, V. Vincek, P. Scibelli, and L. Kong, "CD4 regulatory $\mathrm{T}$ cells prevent lethal autoimmunity in IL-2R $\beta$ deficient mice: implications for the nonredundant function of IL-2," Immunity, vol. 17, no. 2, pp. 167-178, 2002.

[23] M. K. Kennedy, M. Glaccum, S. N. Brown, et al., "Reversible defects in natural killer and memory CD8 T cell lineages in interleukin 15-deficient mice," Journal of Experimental Medicine, vol. 191, no. 5, pp. 771-780, 2000.

[24] M. Aringer, G. H. Stummvoll, G. Steiner, et al., "Serum interleukin-15 is elevated in systemic lupus erythematosus," Rheumatology, vol. 40, no. 8, pp. 876-881, 2001.

[25] L. Baranda, H. de la Fuente, E. Layseca-Espinosa, et al., "IL15 and IL-15R in leucocytes from patients with systemic lupus erythematosus," Rheumatology, vol. 44, no. 12, pp. 1507-1513, 2005.

[26] I. B. Mcinnes, J. Al-Mughales, M. Field, et al., "The role of interleukin-15 in T-cell migration and activation in rheumatoid arthritis," Nature Medicine, vol. 2, no. 2, pp. 175-182, 1996.

[27] C. Gabay and I. B. McInnes, "The biological and clinical importance of the 'new generation' cytokines in rheumatic diseases," Arthritis Research and Therapy, vol. 11, no. 3, article 230, 2009.

[28] E.-L. Allard, M.-P. Hardy, J. Leignadier, et al., "Overexpression of IL-21 promotes massive $\mathrm{CD}^{+}$memory T cell accumulation," European Journal of Immunology, vol. 37, no. 11, pp. 3069-3077, 2007.

[29] K. Ozaki, R. Spolski, R. Ettinger, et al., "Regulation of B cell differentiation and plasma cell generation by IL-21, a novel inducer of Blimp-1 and Bcl-6," Journal of Immunology, vol. 173, no. 9, pp. 5361-5371, 2004.

[30] A. H. Sawalha, K. M. Kaufman, J. A. Kelly, et al., "Genetic association of interleukin-21 polymorphisms with systemic lupus erythematosus," Annals of the Rheumatic Diseases, vol. 67, no. 4, pp. 458-461, 2008.

[31] J. A. Bubier, T. J. Sproule, O. Foreman, et al., "A critical role for IL-21 receptor signaling in the pathogenesis of systemic lupus erythematosus in BXSB-Yaa mice," Proceedings of the National Academy of Sciences of the United States of America, vol. 106, no. 5, pp. 1518-1523, 2009.

[32] R. Ettinger, S. Kuchen, and P. E. Lipsky, "The role of IL21 in regulating B-cell function in health and disease," Immunological Reviews, vol. 223, no. 1, pp. 60-86, 2008.

[33] H. Mitoma, T. Horiuchi, Y. Kimoto, et al., "Decreased expression of interleukin-21 receptor on peripheral B lymphocytes in systemic lupus erythematosus," International Journal of Molecular Medicine, vol. 16, no. 4, pp. 609-615, 2005.

[34] L. M. D'Cruz and L. Klein, “Development and function of agonist-induced $\mathrm{CD} 25^{+} \mathrm{Foxp} 3^{+}$regulatory $\mathrm{T}$ cells in the absence of interleukin 2 signaling," Nature Immunology, vol. 6, no. 11, pp. 1152-1159, 2005.

[35] J. Dhein, H. Walczak, C. Baumler, K.-M. Debatin, and P. H. Krammer, "Autocrine T-cell suicide mediated by APO1/(Fas/CD95)," Nature, vol. 373, no. 6513, pp. 438-441, 1995.

[36] H.-K. Sytwu, R. S. Liblau, and H. O. McDevitt, "The roles of Fas/APO-1 (CD95) and TNF in antigen-induced programmed 
cell death in T cell receptor transgenic mice," Immunity, vol. 5, no. 1, pp. 17-30, 1996.

[37] Z. Dai, A. Arakelov, M. Wagener, B. T. Konieczny, and F. G. Lakkis, "The role of the common cytokine receptor $\gamma$-chain in regulating IL-2- dependent, activation-induced $\mathrm{CD}^{+} \mathrm{T}$ cell death," Journal of Immunology, vol. 163, no. 6, pp. 3131-3137, 1999.

[38] A. La Cava, "T-regulatory cells in systemic lupus erythematosus," Lupus, vol. 17, no. 5, pp. 421-425, 2008.

[39] J.-H. Lee, L.-C. Wang, Y.-T. Lin, Y.-H. Yang, D.-T. Lin, and B.L. Chiang, "Inverse correlation between $\mathrm{CD} 4^{+}$regulatory $\mathrm{T}$ cell population and autoantibody levels in paediatric patients with systemic lupus erythematosus," Immunology, vol. 117, no. 2, pp. 280-286, 2006.

[40] X. Valencia, C. Yarboro, G. Illei, and P. E. Lipsky, “Deficient $\mathrm{CD} 4{ }^{+} \mathrm{CD} 25$ high $\mathrm{T}$ regulatory cell function in patients with active systemic lupus erythematosus," Journal of Immunology, vol. 178, no. 4, pp. 2579-2588, 2007.

[41] C. S. Via, G. C. Tsokos, B. Bermas, M. Clerici, and G. M. Shearer, "T cell-antigen-presenting cell interactions in human systemic lupus erythematosus: evidence for heterogeneous expression of multiple defects," Journal of Immunology, vol. 151, no. 7, pp. 3914-3922, 1993.

[42] G. C. Tsokos, "Overview of cellular immune function in systemic lupus erythematosus," in Systemic Lupus Erythematosus, R. G. Lahita, Ed., pp. 29-92, Academic Press, 4th edition, 2004.

[43] T. R. Malek, B. O. Porter, E. K. Codias, P. Scibelli, and A. Yu, "Normal lymphoid homeostasis and lack of lethal autoimmunity in mice containing mature T cells with severely impaired IL-2 receptors," Journal of Immunology, vol. 164, no. 6, pp. 2905-2914, 2000.

[44] T. R. Malek, A. Yu, P. Scibelli, M. G. Lichtenheld, and E. K. Codias, "Broad programming by IL-2 receptor signaling for extended growth to multiple cytokines and functional maturation of antigen-activated T cells," Journal of Immunology, vol. 166, no. 3, pp. 1675-1683, 2001.

[45] L. P. Cousens, J. S. Orange, and C. A. Biron, "Endogenous IL-2 contributes to T cell expansion and IFN- $\gamma$ production during lymphocytic choriomeningitis virus infection," Journal of Immunology, vol. 155, no. 12, pp. 5690-5699, 1995.

[46] J. Huang, K. W. Kerstann, M. Ahmadzadeh, et al., "Modulation by IL- 2 of CD70 and CD27 expression on CD8 ${ }^{+} \mathrm{T}$ cells: importance for the therapeutic effectiveness of cell transfer immunotherapy," Journal of Immunology, vol. 176, no. 12, pp. 7726-7735, 2006.

[47] A. F. Ochsenbein, S. R. Riddell, M. Brown, et al., "CD27 expression promotes long-term survival of functional effectormemory $\mathrm{CD}^{+}$cytotoxic T lymphocytes in HIV-infected patients," Journal of Experimental Medicine, vol. 200, no. 11, pp. 1407-1417, 2004.

[48] V. Peperzak, Y. Xiao, E. A. M. Veraar, and J. Borst, "CD27 sustains survival of CTLs in virus-infected nonlymphoid tissue in mice by inducing autocrine IL-2 production," Journal of Clinical Investigation, vol. 120, no. 1, pp. 168-178, 2010.

[49] P. Blanco, V. Pitard, J.-F. Viallard, J.-L. Taupin, J.-L. Pellegrin, and J.-F. Moreau, "Increase in activated CD8 ${ }^{+} \mathrm{T}$ lymphocytes expressing perforin and granzyme B correlates with disease activity in patients with systemic lupus erythematosus," Arthritis and Rheumatism, vol. 52, no. 1, pp. 201-211, 2005.

[50] J. A. James, K. M. Kaufman, A. D. Farris, E. Taylor-Albert, T. J. A. Lehman, and J. B. Harley, "An increased prevalence of Epstein-Barr virus infection in young patients suggests a possible etiology for systemic lupus erythematosus," Journal of Clinical Investigation, vol. 100, no. 12, pp. 3019-3026, 1997.
[51] B. D. Poole, A. K. Templeton, J. M. Guthridge, E. J. Brown, J. B. Harley, and J. A. James, "Aberrant Epstein-Barr viral infection in systemic lupus erythematosus," Autoimmunity Reviews, vol. 8, no. 4, pp. 337-342, 2009. 


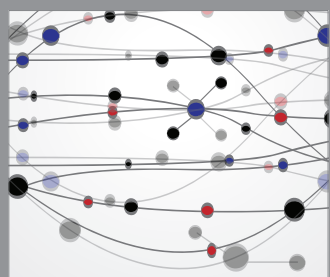

The Scientific World Journal
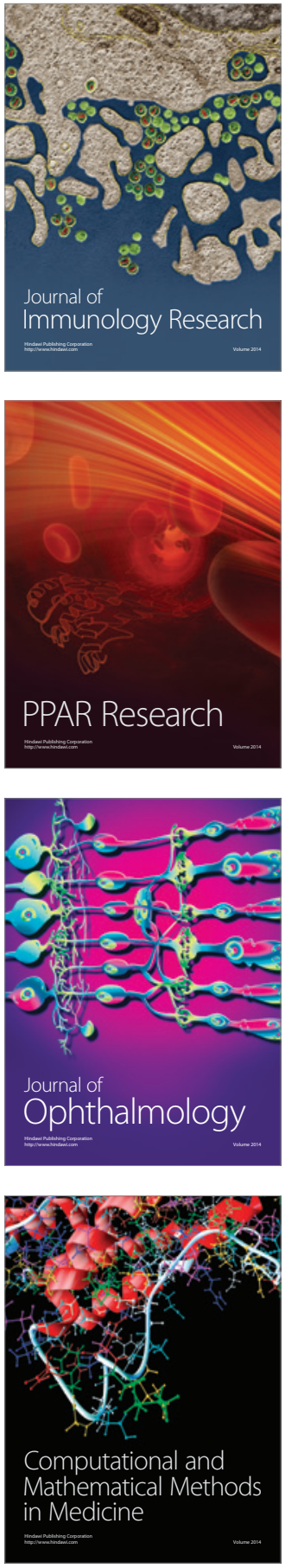

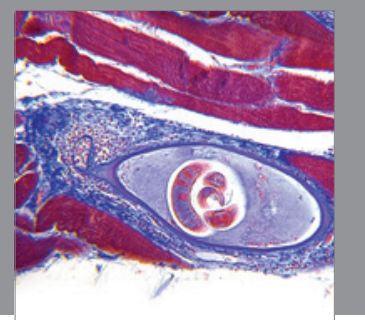

Gastroenterology

Research and Practice
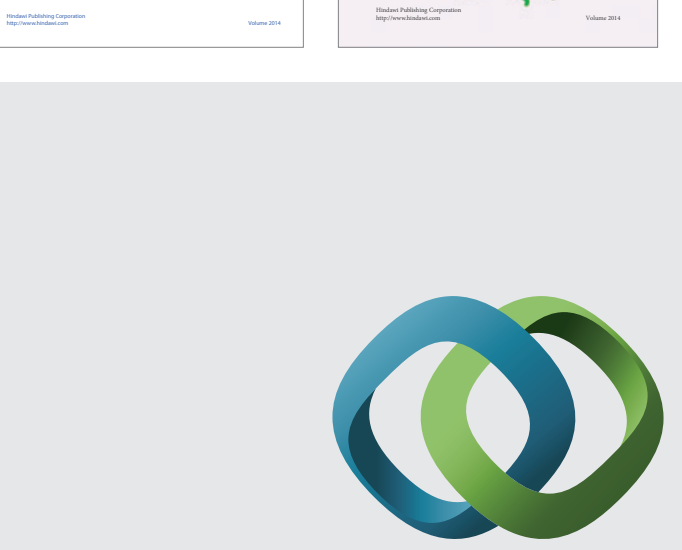

\section{Hindawi}

Submit your manuscripts at

http://www.hindawi.com
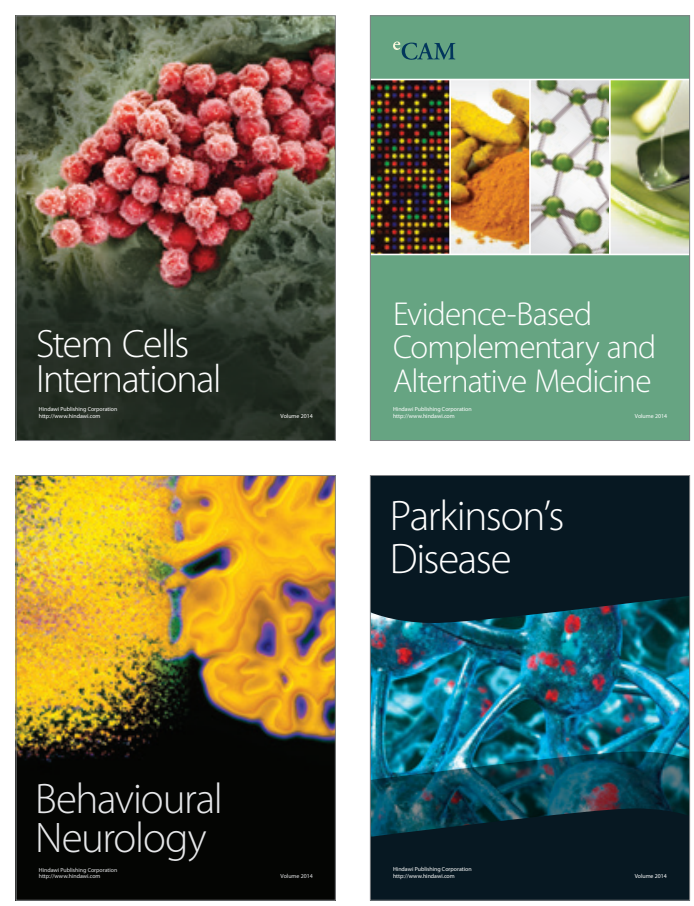

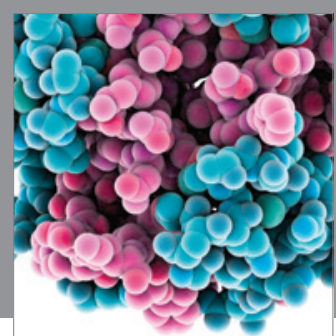

Journal of
Diabetes Research

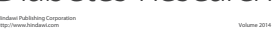

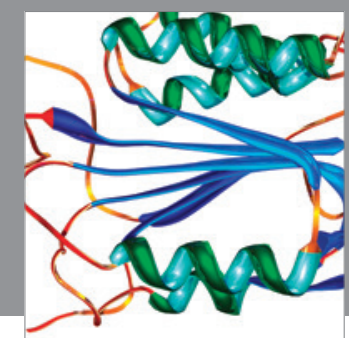

Disease Markers
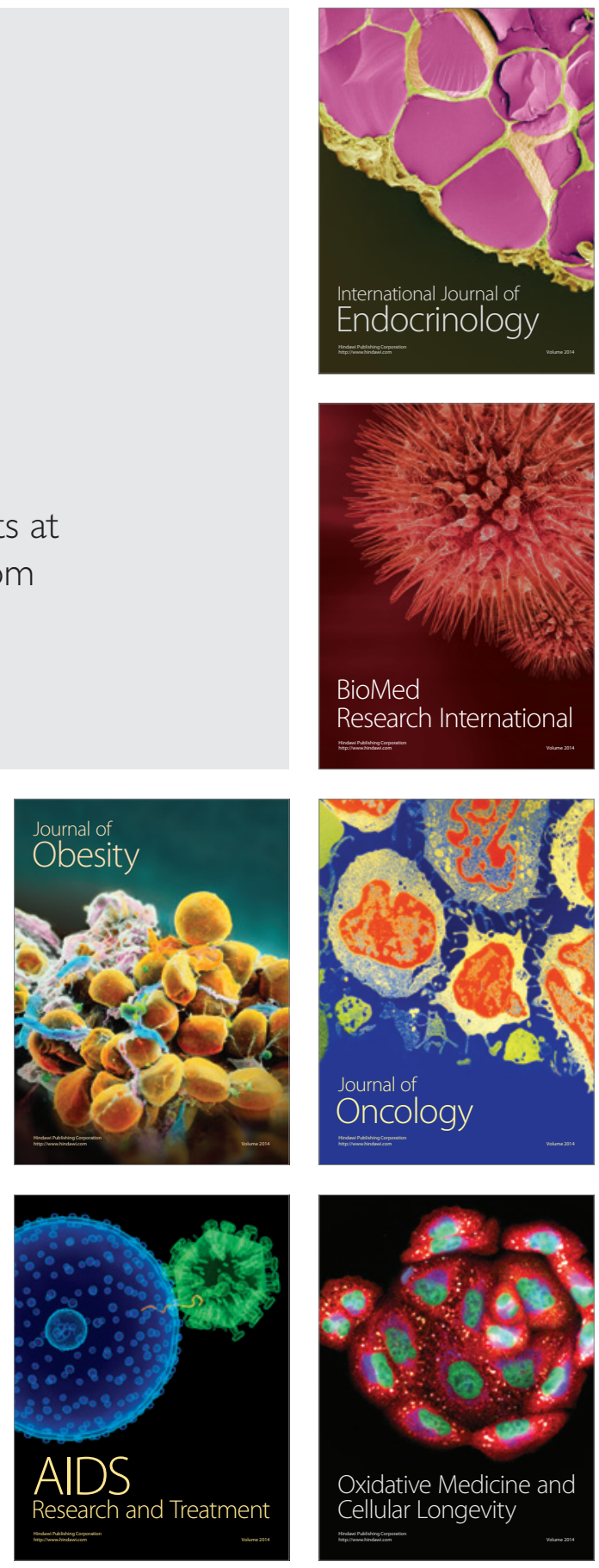